\title{
A Comparison of the Mating Behavior of Adolescent and Adult Female Rhesus Macaques (Macaca mulatta)
}

\author{
Susan Perry and Joseph H. Manson \\ The University of Michigan
}

\begin{abstract}
This study compares adult and adolescent female rhesus macaques with regard to (1) characteristics of their copulatory partners, (2) their proceptive behaviors, and (3) adult male behaviors toward them during estrus. We conducted focal follows of 24 adolescent and 65 adult free-ranging estrous female rhesus macaques on Cayo Santiago during two mating seasons. Compared to adult females, adolescents presented sexually to males at higher rates; copulated more frequently with rankless young male, and extra-group males; and, in one of two mating seasons, were ignored more frequently by males to whom they presented sexually. Adolescents tended to copulate with ranked, resident males at higher frequencies on days when the operational sex ratio (adult males:estrous adult females) was high. Males directed "muzzle-up" signals to adolescents at lower rates than to adults in one of two mating seasons, although this effect vanished when males who might have fathered adolescent females were excluded from analysis. Adolescents did not differ consistently from adults in strength of the correlation between proximity maintenance (dyadic Hinde's Index) and copulation rate, or in approach rate to males. Adolescent females, relative to adult females, presented sexually more to rankless young males, but did not present more to ranked, resident males. Both proximate (e.g. endocrine) and ultimate (e.g. differential fecundity; femalefemale mate competition) explanations may account for the reported differences between adult and adolescent female rhesus macaque sexuality.
\end{abstract}

Key Words: Sexual behavior; Macaca mulatta; Adolescence; Cayo Santiago.

\section{INTRODUCTION}

Only a few studies of free-ranging nonhuman primates have systematically examined differences between adult and adolescent female sexual behavior. Among olive baboons and chimpanzees, adolescents solicit copulations from males at higher rates than adults (RASMUSSEN, 1983; GoOdall, 1986). The opposite may be true among mountain gorillas (WATTS, 1990). Compared to adults, adolescent olive baboons solicit matings from males of a greater variety of ages, including young adults from other groups (SCOTT, 1984). An adolescent's first copulations are likely to be with natal males (PACKER, 1979), whereas adult females copulate mostly with immigrant males. Adolescents' copulatory partners tend to be younger males, rather than fully adult males, in bonnet macaques (GliCK, 1980), olive baboons (RANSOM, 1981; SCOTT, 1984; SMUTS, 1985), and mountain gorillas (WATTS, 1990). A smaller proportion of adolescent females, compared to adults, are mounted by adult male Japanese macaques (WOLFE, 1978). Adolescent female longtailed macaques are more likely than adults to copulate with low-ranking males (vAN NoORDWIJK, 1985). Adolescent female chimpanzees, unlike adults, sometimes try to solicit copulations from males that have shown no sexual interest in them (PUSEY, 1978).

Comparable data bearing on these issues are not available for rhesus macaques, although a number of studies have shown differences in endocrine profiles and estrous period lengths 
between adolescents and adults (e.g. FOSTER, 1977; WILSON et al., 1982). In this paper, we compare adult and adolescent female rhesus macaques with regard to (1) characteristics of their copulatory partners, (2) their proceptive behaviors, and (3) adult male behaviors toward them during estrus. By comparing rates or frequencies of courtship behaviors, as well as copulations, among heterosexual dyads, we seek to present a preliminary description of adolescent-adult differences - if any - in mate preferences and attractivity to males. We define mate choice as "any pattern of behavior, shown by members of one sex, that leads to their being more likely to mate with certain members of the opposite sex than others" (HALLIDAY, 1983: 4).

\section{METHODS}

\section{Study Site AND SubJects}

Our subjects were female rhesus macaques of two social groups (Groups $\mathrm{T}$ and $\mathrm{Q}$ ) on Cayo Santiago, a 15-ha island $1 \mathrm{~km}$ off the southeast coast of Puerto Rico. These monkeys are provisioned with monkey chow and water, and are trapped once a year, at which time the infants are tattooed and earmarked for identification purposes. A biweekly census of the entire population updates a database of births, deaths, intergroup transfers, and group fissions covering the entire period since 1956. Periodic removal of entire social groups keeps the population between approximately $600-1400$. Otherwise, the monkeys are free-ranging and are not handled or interfered with. For further information about Cayo Santiago management and history, see Altmann (1962), SADE et al. (1985), and RAWLins and KESSLER (1986).

Table 1 summarizes the numbers of adult and adolescent females available in each study group in each year of the study and shows the amount of data collected on each of these females. Females 4.5 yrs old and older were classified as adults, whereas females $2.5-3.5$ yrs old were classified as adolescents. Only one 2.5 -yr-old female came into estrus during the study.

Table 1. Females included in the sample and hours of focal data collected on each group.

\begin{tabular}{lllrccc} 
Year & Group & Age class & No. in group & No. in sample & No. of focal hours & Range: hours/female \\
\hline 1988 & T & Adult & 21 & 16 & 123.0 & $3.0-21.5$ \\
1988 & T & Adolescent & 9 & 9 & 63.5 & $1.5-12.5$ \\
1988 & Q & Adult & 29 & 23 & 119.5 & $2.0-15.5$ \\
1988 & Q & Adolescent & 7 & 7 & 83.5 & $4.5-19.5$ \\
1989 & T & Adult & 27 & $16^{\text {a) }}$ & 95.5 & $1.5-16.0$ \\
1989 & T & Adolescent & 4 & 3 & 35.0 & $6.5-21.5$ \\
1989 & Q & Adult & 36 & $26^{\text {a) }}$ & 392.0 & $3.0-67.0$ \\
1989 & Q & Adolescent & 6 & 6 & 107.0 & $3.5-49.0$ \\
\hline
\end{tabular}

a) Includes three females that were adolescents in 1988 .

\section{Measures And Definitions}

Mating pairs of rhesus macaques usually engage in multiple mounts before the final ejaculatory mount, discernible by a characteristic pause and rigid posture by the male. 
Mount series or single mounts ending in ejaculation will be called "copulations." Adult females experienced clearly discernible "attractiveness breakdowns" [sharp decreases in sexual attractiveness between one day and the next - see CHAPAIS (1983) and MANSON (1992) for details], but adolescents did not. We regarded an adult female as being in estrus from the day she was first seen in a mount series, or with a mating plug (coagulated ejaculate on her perineum), until the day after her attractiveness breakdown. Adolescent females were regarded as being in estrus on any day during which they were seen in a mount series or with a mating plug.

Other behaviors analyzed in this paper are defined as follows:

Hinde's Index: For each male-estrous female dyad in which the sum of observed approaches and leaves during focal follows was at least ten, we calculated Hinde's Index (HINDE \& ATKINSON, 1970) by subtracting the proportion of all leaves within the dyad that were performed by the female from the proportion of all approaches within the dyad that were performed by the female. Thus, a dyad having a Hinde's Index score of +1 is one in which the female is entirely responsible for maintaining proximity within the pair. An approach was defined as one animal decreasing the distance between itself and another animal by at least one half meter and stopping or sitting, with the final distance between them being less than $4 \mathrm{~m}$. A leave was defined as one animal increasing the distance between itself and another animal by at least one half meter, with the initial distance between them being less than $4 \mathrm{~m}$. Approaches and leaves taking place at the artificial drinking stations were excluded from analyses. Adult estrous female proximity maintenance to males was validated as a mate choice signal (MANSON, 1992).

Muzzle-up: This is a gesture performed by males in the mating season and directed at estrous females. It consists of a rapid smacking of the lips, flattening of the ears, and turning of the head. Sometimes it is accompanied by stalking. We use rate of this behavior as a measure of male courtship intensity.

Ignoring of Female Present: When a female presented sexually to a male, and the male did not respond by mounting her, this interaction was scored as an ignore.

\section{Data Collection and Analysis}

The data presented in this paper were collected by $1-4$ observers on 162 days during one complete mating season (June - October 1988) and seven weeks of a second mating season (June-August 1989). To ensure inter-observer reliability, all observers were required to meet a standard of $90 \%$ concurrent records, over 4 consecutive 30 -min focal follows. Data collected during test sessions were not analyzed. Two observers collected focal data during the 1988 mating season, and three observers during the 1989 mating season; all observers collected data on both social groups. An additional field assistant monitored the reproductive state of all females in the two study groups daily, during both mating seasons. Ad lib observations (AltMAnN, 1974) during the birth seasons preceding each mating season provided some information about dominance relationships.

Two-hour focal individual follows (AltmanN, 1974), divided into 30-min sampling blocks with no more than 5 min between them, were conducted on females chosen randomly from among all females judged to be in estrus. Because focal animals were chosen at 
Table 2. Males of the study groups.

\begin{tabular}{|c|c|c|c|c|c|c|c|}
\hline Year & Group & $\begin{array}{l}\text { No. of natal } \\
\text { rankless males }{ }^{a}\end{array}$ & $\begin{array}{l}\text { No. of natal } \\
\text { ranked males }\end{array}$ & $\begin{array}{l}\text { No. of } \\
\text { immigrant } \\
\text { males }\end{array}$ & $\begin{array}{l}\text { No. of } \\
\text { possible } \\
\text { fathers }\end{array}$ & $\begin{array}{l}\text { Mean age } \\
\text { of possible } \\
\text { fathers }^{c)}(\mathrm{yrs})\end{array}$ & $\begin{array}{l}\text { Mean dominance } \\
\text { rank of possible } \\
\text { fathers }^{\text {c), d) }}\end{array}$ \\
\hline 1988 & $\mathrm{Q}$ & 10 & 4 & 22 & 3 & 11.7 & .83 \\
\hline 1988 & $\mathrm{~T}$ & 8 & 3 & 31 & 6 & 12.6 & .82 \\
\hline 1989 & $\mathrm{Q}$ & 11 & 5 & 18 & 5 & 12.6 & .70 \\
\hline 1989 & $\mathrm{~T}$ & 12 & 4 & 30 & 7 & 12.9 & .74 \\
\hline
\end{tabular}

a) Age: $3.5-5.5$ yrs; b) age: $5.5-8.5$ yrs; c) of adolescent (3.5-yr-old) females (see text for details); d) proportion of group males dominated.

random, some estrous females were never sampled, and there is wide variation in the amount of data collected per female (Table 1). Data from incomplete sampling blocks were discarded from analyses of focal data. During focal follows, all approaches, leaves, and occurrences of 54 social behaviors were recorded on a continuous basis. The Cayo Santiago longterm database provided information about ages of subjects, kinship through the maternal line, births of focal subjects' infants, and (for males) dates of immigration and emigration. Possible fathers of adolescents were defined as males that had immigrated into the adolescent (3.5-yr-old) cohort's social group no later than December of the calendar year preceding the birth year of the cohort (although the complete mating season that we observed ended in October, infants have been conceived as late as December in past mating seasons, as shown by the longterm database). Table 2 shows that possible fathers of adolescents were mostly older, high-ranking males, and that they comprised only a small proportion of each social group's adult males. Table 2 also shows the numbers of natal males in each study group in each mating season. Natal males are divided into those lacking, and those possessing, consistent individual ranks in the male dominance hierarchy.

For each day of data collection during the 1988 mating season (the only complete mating season of the study), we calculated the operational sex ratio (OSR) for each social group as the number of resident males 5 yrs and older, divided by the number of adult estrous females. OSR values were dichotomized into low (below the median) and high (above the median).

Ideally, variation in female reproductive maturity within the adolescent age class would have been assessed using hormonal data. Instead, we used reproductive performance as a measure of maturity: adolescents that conceived were probably more mature than those that failed to conceive. Thus, for some analyses of 1988 mating season data (those for which sufficient sample sizes were available), adolescent females were divided into those that produced live infants during the following birth season ("conceived") and those that apparently did not conceive. Fetal losses, if they occurred, were not detectable by observers.

Sample sizes vary throughout this paper because data on all of the variables of interest are not available for all females. For example, some adolescents were not observed to copulate during focal observations. A total of 284 focal hrs were collected on adolescent females, and $730 \mathrm{hrs}$ of focal data were collected on adult estrous females, including estrous cycles that were truncated by the end of the study in August 1989 (MANSON, 1992). Estrous periods were not divided into peri-ovulatory and non-peri-ovulatory phases as by MANSON (1992), because adolescents' "attractiveness breakdowns" (CHAPAIS, 1983), marking the end of the 4-day peri-ovulatory period (CATCHPOLE \& VAN WAGENEN, 1978; GORDON, 1981) were not reliably discernible as they were in adults, possibly because some adolescents' estrous cycles were anovulatory. Thus, to make the samples more comparable, 
we did not distinguish peri-ovulatory from non-peri-ovulatory copulations in either adolescents or adults.

Variation in quantity of data collected on focal subjects should not bias our results, because all analyses were based on (1) hourly rates of behavior, (2) proportions of individual females' mates in different categories, and/or (3) Hinde's Index. However, because (1) all estrous females were eligible for random selection as focal subjects on each day, and (2) adolescent females have been observed to exhibit longer mating periods and longer follicular phases than adults in captive settings (WILSON et al., 1982), our sampling procedure entailed the risk of biasing our comparisons between adolescents and adults. Specifically, a higher proportion of focal observation time of adults (compared to adolescents) may have occurred during their peri-ovulatory periods, when they would be expected to be more sexually attractive. We therefore calculated estrous period lengths ( $\bar{X} \pm S E$ days) of all estrous females for whom we were able to discern discrete mating periods in the 1988 mating season, and compared adults to adolescents. If adolescents' estrous periods were significantly longer than adults', correction for this bias would be necessary. We did not use 1989 data in this comparison because our 1989 observations were truncated by the end of the study.

All statistical tests are two-tailed. "Statistical significance" denotes that $p<.05$.

\section{RESULTS}

\section{Estrous Period Lengths}

Adolescents' estrous periods were not significantly longer than adults' estrous periods in the 1988 mating season $\left(N_{l}=10\right.$ adolescents, $N_{2}=40$ adults, $X_{1}=17.20 \pm 2.82, X_{2}=$ $13.92 \pm .58$, Unpaired $t$-test, $p>.05$ ).

\section{Ability to Exert Mate Choice}

To examine whether adolescents would be less capable of exerting mate choice than would adults, we plotted Hinde's Index against hourly copulation rate for all male-estrous female dyads with at least ten summed approaches and leaves. Table 3 shows the results. Considering each female age class in each social group during each mating season as a

Table 3. Hinde's index in relation to copulation rate (Kendall rank test).

\begin{tabular}{lrrr}
\hline Sample & $N^{\mathrm{a})}=$ & $\tau$ & $p^{\mathrm{b})}=$ \\
\hline Q+ T adolescents 1988 & 114 & .281 & .000 \\
Q+T adults 1988 & 228 & .080 & .072 \\
Q adolescents 1988 & 61 & .327 & .000 \\
Q adults 1988 & 120 & .210 & .001 \\
T adolescents 1988 & 53 & .228 & .016 \\
T adults 1988 & 108 & -.056 & .395 \\
Q+ T adolescents 1989 & 67 & .174 & .037 \\
Q + T adults 1989 & 221 & .209 & .000 \\
Q adolescents 1989 & 55 & .212 & .022 \\
Q adults 1989 & 164 & .189 & .000 \\
T adolescents 1989 & 12 & -.059 & .787 \\
T adults 1989 & 57 & .263 & .004 \\
\hline
\end{tabular}

a) Number of dyads; b) $p$-value of Kendall's $\tau$ for the sample. 
separate test, six of eight correlations were significantly positive while two correlations were non-significant. To test whether the correlation between Hinde's Index and copulation rate was significantly different between adolescents and adults, we performed the following procedure (SNEDECOR \& COCHRAN, 1989). For each female, we calculated the correlation (Kendall's $\tau$ ), across all males with whom she had at least ten summed approaches and leaves, between Hinde's Index and copulation rate. Each female's $\tau$ coefficient was transformed according to SNEDECOR and COCHRAN (1989: 474), using the formula $z=(1 / 2)$ $\ln (1+\tau) /(1-\tau)$. Adolescents' transformed $\tau$ coefficients were compared to adults' transformed $\tau$ coefficients using a two-tailed unpaired $t$-test. For Groups $T$ and $Q$ combined in 1988, the correlations between Hinde's Index and copulation rate did not differ significantly for adolescents vs adults $(p=0.329)$, although adolescents tended to have stronger correlations. In 1989, the correlation was significantly stronger among adults than among adolescents $(p=0.046)$. Thus, both adolescents and adults tended to exercise mate choice via proximity maintenance [see MANSON (1992) for consideration of differences between social groups]. Adolescents and adults did not differ consistently in the degree to which they exercised mate choice via proximity maintenance.

\section{Female Assertiveness}

There was no significant difference between adolescent females and adult females in the rate at which they approached males (Table 4). However, in both mating seasons of the study, adolescents presented sexually to males at significantly higher rates than did adult females (Table 5). Among the 1988 adolescents, this difference was accounted for largely by differences between adults and non-conceiving adolescents. However, when conceiving and non-conceiving adolescents' present rates were compared directly, they did not differ significantly.

Table 4. Hourly rates of estrous female approaches to males (Mann-Whitney $U$-tests).

\begin{tabular}{llll}
\hline Sample & $N=$ & Means & $p=$ \\
\hline Females 1988 & 16 adolescents & Adolescents: 11.27 & .58 \\
& 39 adults & Adults: 11.73 & \\
Females 1989 & 9 adolescents & $\begin{array}{l}\text { Adolescents: } 5.67 \\
\text { Adults: } 6.85\end{array}$ & .29 \\
\hline
\end{tabular}

Table 5. Hourly rates of female sexual presents to males (Mann-Whitney $U$-tests).

\begin{tabular}{llll}
\hline Sample & $N=$ & Means & $p=$ \\
\hline All females 1988 & 39 adults & Adults: 1.04 & .006 \\
& 16 adolescents & Adolescents: 1.87 & .16 \\
Adults \& conceiving & 39 adults & Adults: 1.04 & \\
adolescents 1988 & 10 conceiving adolescents & Conceiving adolescents: 1.63 & .08 \\
Adults \& non-conceiving & 39 adults & Adults: 1.04 & \\
adolescents 1988 & 4 non-conceiving adolescents & Non-conceiving adolescents: 2.31 & .32 \\
Adolescents 1988 & 10 conceiving & Conceiving: 1.63 & .012 \\
& 4 non-conceiving & Non-conceiving: 2.31 & Adults: .62 \\
All females 1989 & 43 adults & Adolescents: 1.09 & \\
& 9 adolescents & & \\
\hline
\end{tabular}




\section{Age/RAnK/Residency CATEgories of Mates}

Adolescent females differed from adult females in the age/rank/residency categories of their copulatory partners. We divided all males into two categories: (1) $R=$ those that were resident in the female's social group and had a consistent rank in the dominance hierarchy and (2) NX=those that were either (a) 3.5-5.5-yr-old natal males that were not yet integrated into the male hierarchy or (b) extra-group - i.e. solitary or resident in another social group. Comparing the proportions, rather than the absolute numbers, of copulatory partners in the two age/rank/residency categories controls for differences between categories in numbers of individuals. In both mating seasons, a higher proportion of adult females' copulatory partners than of adolescents' copulatory partners were in the $\mathrm{R}$ category (1988: $N_{I}=12$ adolescents, $N_{2}=37$ adults, $U=78, p=.0001 ; 1989: N_{I}=7, N_{2}=33$, $U=24, p=.0006$ ). We divided $\mathrm{R}$ males further into (1) possible fathers of adolescent females (RPF) and (2) males that could not have fathered adolescent females (RNF). In 1989, a higher proportion of adult females' copulatory partners than of adolescents' copulatory partners were in the RNF category $(U=26.5, p=.001)$. In 1988 this result failed to attain statistical significance $(U=147, p=.07)$. Rank/age/residency categories of mates did not differ between adolescents that conceived and those that failed to conceive. Table 6 shows

Table 6. Proportions of a female's copulatory partners during focal observations by category of male, averaged over all females.

\begin{tabular}{|c|c|c|c|c|c|c|}
\hline \multirow[b]{2}{*}{ Year } & \multirow[b]{2}{*}{ Group } & \multirow[b]{2}{*}{ Sample } & \multicolumn{4}{|l|}{ Category of male } \\
\hline & & & $\begin{array}{l}\text { Ranked/resident/ } \\
\text { non-father }\end{array}$ & $\begin{array}{l}\text { Ranked/resident/ } \\
\text { possible father }{ }^{\text {b) }}\end{array}$ & Natal/rankless & Extra-group \\
\hline 1988 & $\mathbf{T}$ & Adult & .53 & .43 & 0 & .04 \\
\hline 1988 & $\mathbf{T}$ & Adolescent & .29 & 0 & .25 & .46 \\
\hline 1988 & $\mathrm{~T}$ & Adolescent conceivers & .31 & 0 & .38 & .31 \\
\hline 1988 & $\mathrm{~T}$ & Adolescent non-conceivers & 0 & 0 & 0 & 1.00 \\
\hline 1988 & $Q$ & Adult & .75 & .07 & .10 & .08 \\
\hline 1988 & $\mathrm{Q}$ & Adolescent & .54 & .08 & .38 & 0 \\
\hline 1988 & $\mathrm{Q}$ & Adolescent conceivers & .44 & .12 & .44 & 0 \\
\hline 1988 & $Q$ & Adolescent non-conceivers & .75 & 0 & .25 & 0 \\
\hline 1989 & $\mathrm{~T}$ & Adult & .76 & .11 & .02 & .11 \\
\hline 1989 & $\mathrm{~T}$ & Adolescent & .14 & .14 & .15 & .57 \\
\hline 1989 & $Q$ & Adult & .61 & .10 & .08 & .21 \\
\hline 1989 & $Q$ & Adolescent & .10 & 0 & .51 & .39 \\
\hline
\end{tabular}

a) Could not have fathered adolescent (3.5-yr-old) females (see text for details); b) of adolescent (3.5-yr-old) females (see text for details).

the mean proportions of adolescents' and adults' copulatory partners of different male categories. We have divided the results by social group, and divided the NX category into natal rankless and extra-group males, for illustrative purposes. No NX males were possible fathers of adolescents.

We examined the age/rank/residency categories of adolescent females' copulatory partners as a function of operational sex ratio (OSR). If females compete to copulate with $R$ males, and if adults usually win this competition against adolescents, it would be expected that adolescent females would copulate more frequently with NX males when the OSR is 
Table 7. Operational sex ratio and copulations with ranked/resident and natal/rankless or extragroup males.

\begin{tabular}{|c|c|c|c|c|}
\hline \multirow[b]{2}{*}{ Female } & \multicolumn{2}{|l|}{$\mathrm{High}^{\text {a) }} \mathrm{OSR}^{\mathrm{b})}$} & \multicolumn{2}{|l|}{ Low $^{\mathrm{c})} \mathrm{OSR}^{\mathrm{b})}$} \\
\hline & $\begin{array}{l}\text { No. of copulations } \\
\text { with ranked/resident } \\
\text { males }\end{array}$ & $\begin{array}{l}\text { No. of copulations } \\
\text { with natal/rankless } \\
\text { or extra-group males }\end{array}$ & $\begin{array}{l}\text { No. of copulations } \\
\text { with ranked/resident } \\
\text { males }\end{array}$ & $\begin{array}{l}\text { No. of copulations } \\
\text { with natal/rankless } \\
\text { or extra-group males }\end{array}$ \\
\hline \multicolumn{5}{|c|}{ Group Q } \\
\hline$J 13$ & 2 & 0 & 1 & 0 \\
\hline 142 & 4 & 0 & 0 & 1 \\
\hline 143 & 0 & 0 & 0 & 1 \\
\hline 134 & 0 & 0 & 7 & 0 \\
\hline 159 & 3 & 0 & 2 & 1 \\
\hline 189 & 0 & 0 & 3 & 1 \\
\hline \multicolumn{5}{|c|}{ Group $\mathrm{T}$} \\
\hline 181 & 3 & 1 & 0 & 0 \\
\hline 155 & 0 & 2 & 0 & 3 \\
\hline J07 & 1 & 1 & 0 & 0 \\
\hline 138 & 0 & 2 & 0 & 0 \\
\hline 194 & 0 & 2 & 0 & 1 \\
\hline
\end{tabular}

a) Above the median; b) number of resident males 5 yrs and older, divided by the number of adult estrous females, on the day of the copulation; c) below the median.

low than when it is high. Table 7 shows a trend in this direction: Group $\mathrm{Q}$ adolescent females copulated with NX males only when the OSR was low; Group T adolescent females completed no copulations with $\mathrm{R}$ males when the OSR was low.

\section{COURTSHIP BY MALES}

Table 8 shows that males directed "muzzle-up" courtship signals toward adult females at significantly higher rates than toward adolescent females in 1989. However, this result was accounted for entirely by differences in the courtship behavior of males that were possible fathers of adolescents. In 1988 also, possible fathers of adolescents directed muzzle-ups toward adult females at significantly higher rates than toward adolescents. Because some possible fathers of adolescents were also possible fathers of young adult females, this is a conservative test of the association between possible paternity and male courtship intensity;

Table 8. Hourly rates of muzzle-ups to females (Mann-Whitney $U$-tests).

\begin{tabular}{|c|c|c|c|}
\hline Sample & $N=$ & Means & $p=$ \\
\hline All females \& all males 1988 & $\begin{array}{l}16 \text { adolescents } \\
39 \text { adults }\end{array}$ & $\begin{array}{l}\text { Adolescents: } .030 \\
\text { Adults: } .036\end{array}$ & .152 \\
\hline $\begin{array}{l}\text { All females } \\
\text { Possible fathers }{ }^{\text {a) }} \text { only } 1988\end{array}$ & $\begin{array}{l}16 \text { adolescents } \\
39 \text { adults }\end{array}$ & $\begin{array}{l}\text { Adolescents: } .032 \\
\text { Adults: } .117\end{array}$ & .024 \\
\hline $\begin{array}{l}\text { All females } \\
\text { Non-fathers }{ }^{\text {b) }} \text { only } 1988\end{array}$ & $\begin{array}{l}16 \text { adolescents } \\
39 \text { adults }\end{array}$ & $\begin{array}{l}\text { Adolescents: } .027 \\
\text { Adults: } .027\end{array}$ & 1.00 \\
\hline All females \& all males 1989 & $\begin{array}{l}9 \text { adolescents } \\
42 \text { adults }\end{array}$ & $\begin{array}{l}\text { Adolescents: } .021 \\
\text { Adults: } .045\end{array}$ & .008 \\
\hline $\begin{array}{l}\text { All females } \\
\text { Possible fathers }{ }^{\text {a) }} \text { only } 1989\end{array}$ & $\begin{array}{l}9 \text { adolescents } \\
42 \text { adults }\end{array}$ & $\begin{array}{l}\text { Adolescents: } .012 \\
\text { Adults: } .136\end{array}$ & .0002 \\
\hline $\begin{array}{l}\text { All females } \\
\text { Non-fathers }{ }^{\text {b) }} \text { only } 1989\end{array}$ & $\begin{array}{l}9 \text { adolescents } \\
42 \text { adults }\end{array}$ & $\begin{array}{l}\text { Adolescents: } .020 \\
\text { Adults: } .031\end{array}$ & .159 \\
\hline
\end{tabular}

a) Of adolescent (3.5-yr-old) females (see text for details); b) could not have fathered adolescent (3.5-yr-old) females (see text for details). 
i.e. these results indicate the minimum magnitude of this association. However, because group tenure is strongly correlated with male dominance rank, possible paternity of adolescents is unavoidably confounded with high dominance rank (see Table 2). Table 8 shows that muzzle-up rates by possible fathers of adolescents toward adult females were considerably higher than rates toward adult females by non-fathers. In 1988, there was no significant difference between conceiving and non-conceiving adolescents in rates of received muzzle-ups.

\section{Ignoring of Female Proceptive Behavior by Males}

Table 9 shows the proportion of female-initiated sexual presents that were ignored by males. In 1988, males ignored a higher proportion of adolescents' than adults' presents. No presents to possible fathers were observed in 1988. There was no difference between the proportion of conceiving vs non-conceiving adolescents' presents ignored. This result was not significant in 1989.

Table 9. Proportion of sexual presents ignored by males (Mann-Whitney $U$-tests).

\begin{tabular}{|c|c|c|c|}
\hline Sample & $N=$ & Means & $p=$ \\
\hline All females \& all males $1988^{\text {a) }}$ & $\begin{array}{l}16 \text { adolescents } \\
33 \text { adults }\end{array}$ & $\begin{array}{l}\text { Adolescents: } .555 \\
\text { Adults: } .208\end{array}$ & .001 \\
\hline All females \& all males 1989 & $\begin{array}{l}9 \text { adolescents } \\
32 \text { adults }\end{array}$ & $\begin{array}{l}\text { Adolescents: } .359 \\
\text { Adults: } .192\end{array}$ & .074 \\
\hline All females & 9 adolescents & Adolescents: .347 & .100 \\
\hline Non-fathers ${ }^{\text {b) }}$ only 1989 & 32 adults & Adults: .200 & \\
\hline
\end{tabular}

a) No presents to possible fathers were observed in 1988; b) could not have fathered adolescent (3.5-yr-old) females (see text for details). Insufficient data for test using possible fathers only.

\section{Sexual Presents Toward Males by Age/Rank/Residency Categories}

In both study groups in both mating seasons, adolescent females presented sexually at higher rates than adult females toward 3.5 - 5.5-yr-old natal rankless males (Group Q 1988: $N_{l}=7$ adolescents, $N_{2}=23$ adults, $U=21.5, p=.0002$; Group T 1988: $N_{l}=7, N_{2}=16$, $U=32, p=.006$; Group Q 1989: $N_{I}=6, N_{2}=24, U=17, p=.0005$; Group T 1989: $N_{l}=3$, $N_{2}=16, U=8, p=.0006$ ). In Group Q in 1989, adults presented sexually at higher rates than adolescents to ranked resident males $(U=22.5, p=.012)$, but this did not occur in Group T in either mating season (1988: $U=53.5, p>.50 ; 1989: U=18, p>.50$ ) or in Group $Q$ in $1988(U=80.5, p>.50)$. Significance of these results was not changed by excluding possible fathers from the ranked resident male category.

We could not test whether adolescents differed from adults in their proceptive behavior toward extra-group males. Any such test would necessitate designating a set of extra-group males that was socially available to focal females. The identities of the extra-group males that associated with our study groups varied on a daily basis, and we did not systematically record them. Furthermore, the number of extra-group males interacting with members of our study groups appeared to increase over time during the mating season, and adolescents tended to begin their first estrous periods later in the mating seasons than adults. Designating a single set of socially available extra-group males for both adolescent and adult females would therefore introduce bias into any test of whether adolescents showed more proceptive behavior than adults toward extra-group males. 


\section{DISCUSSION}

Our data showed some differences between adult and adolescent female rhesus macaque behavior, although these were not always consistent between mating seasons or between social groups. Adults and adolescents did not appear to differ in their ability to exercise mate choice. Estrous adolescents did not approach males more than adults did, but they presented sexually to them at higher rates. Adolescents' copulatory partners, more than adults', tended to be natal rankless or extra-group males rather than ranked resident males. Males courted adolescents less intensely than they courted adults in one mating season, but this result vanished when possible fathers of adolescents were excluded from the analysis. In one of two mating seasons, males ignored a higher proportion of adolescents' than adults' sexual presents. Compared to adults, adolescents presented sexually at higher rates toward rankless young natal males. Non-conceiving adolescents presented sexually to males at higher rates than conceiving adolescents; no other analyses showed differences between conceiving and non-conceiving adolescents.

Observed sexual behavior results from complex interactions of (1) male and female preferences and (2) constraints on the expression of these preferences [such as male sexual coercion (SMUTS \& SMUTS, 1992)]. Theoretical considerations can generate the competing predictions that adolescent females will prefer to mate with (1) ranked, resident males that have demonstrated their ability to succeed in social competition; or (2) young natal rankless and extra-group mates, as an inbreeding avoidance mechanism, since ranked residents are more likely to be their fathers. Female rhesus macaques, to a greater extent than males, seek to avoid copulations with matrilineal kin residing in the same social group (MANSON \& PERRY, 1993). The only effect on our analyses of dividing ranked resident males into (1) possible fathers and (2) more recent immigrants was that males courted their possible daughters less intensely than they courted older females. Because possible fathers of adolescents tended to be high ranking (Table 2), it is unclear whether this result reflects (1) male sexual avoidance of possible daughters or (2) the greater ability of higher-ranking males, compared to lower-ranking males, to openly court the (possibly more sexually attractive) adult females. Consistent with the second interpretation, muzzle-up rates by possible fathers of adolescents toward adult females were considerably higher than rates toward adult females by non-fathers (Table 8). In neither study group were there enough possible fathers to severely restrict adolescents' mate choices (Table 2).

We did not directly quantify manifestations of female-female competition for mates. Although 3.5-yr-old females had already assumed their genealogically determined place in the female dominance hierarchy (unpubl. data; see also DATTA, 1983), males tended to aid adult mating partners in aggressive interactions against adolescent females. We saw some instances of direct competition between adult and adolescent estrous females (i.e. an adult female threatening an adolescent away from a male that they were both courting), but these were rare. Suggestive evidence (Table 7) indicates that adolescent females were more likely to mate with ranked, resident males (as opposed to natal rankless or extra-group males) when operational sex ratios were high. This is consistent with the hypotheses that (1) estrous females compete for access to preferred ranked, resident males and (2) males prefer to copulate with adults, and are more likely to copulate with adolescents at times when adults are unavailable. However, the prevalence of male attacks on estrous females (CHAPAIS, 1983; MANSON, 1994) complicates the interpretation of this finding. Adolescents may have greater access to preferred ranked, resident males when relatively fewer adult females are competing for, and available to, these males; but alternatively, these males may direct more 
attacks toward estrous adolescent females when fewer adult (i.e. preferred) females are available. On the other hand, it is not known whether male attacks on estrous females increase the likelihood of future copulation between the attacker and the victim.

Several authors (Hanby \& Brown, 1974; PuSEY, 1978; Wolfe, 1978; SCOTT, 1984; GOODALL, 1986; LANCASTER, 1986) have hypothesized that selection on female primates has produced adolescent sterility as an adaptation to the complex social milieus in which courtship and copulation occur. In this view, interactions with males provide adolescents with (1) information on which to base mate choices and (2) the behavioral skills necessary for effective courtship and sexual behavior. Errors made during adolescent sterility may entail lower costs than errors made while fully sexually mature. Thus, adolescence serves to provide females with a period in which to "practice" sexual behavior and mate choice. Our finding that adolescents were more proceptive than adults toward rankless young natal males is consistent with, though not a test of, the idea that adolescents learn the consequences of mating with males of varying ages and dominance ranks. For instance, they may learn that engaging in mount series with low-ranking males increases their vulnerability to attacks by intruding higher-ranking males (MANSON, 1994). Because many attacks occur in secluded areas, adolescents may be unable to learn this contingency by observing other females; direct experience may be necessary.

Adolescent female primates have been hypothesized to be less sexually attractive than adults because of the lower probability that an adolescent will conceive and successfully rear an offspring to independence (ANDERSON, 1986). Two hypothesized proximate mechanisms that yield similar predictions are that adolescents' (1) hormonal profiles [possibly mediated through visual stimuli such as sexual swellings (BIELERT et al., 1985; BIELERT \& Girolami, 1986)] or (2) poorly or clumsily executed mating behaviors (e.g. HANBY \& BRown, 1974; WOLFE, 1978; SCOTT, 1984) make them less attractive to males. Lower attractiveness of adolescent females compared to adults (i.e. male mate choice) could account for our findings that (1) males sometimes ignored adolescents' sexual presents more than they ignored adults' presents, and (2) adolescents were more likely than adults to copulate with the males that are least likely to succeed in male-male competition - i.e. natal rankless and extra-group males. Adolescents that conceived may have been more sexually mature than those that (apparently) failed to conceive; however, males behaved the same toward non-conceiving as toward conceiving adolescents.

Acknowledgements. We thank J. Gros-Louis and A. LAKE for assistance in data collection, and J. Gros-Lours for help computerizing the data. T. CARo, B. Chapais, B. SMuts, Y. TAKahata, and an anonymous reviewer made helpful comments on earlier drafts of the manuscript. A. M. HuRTADO provided statistical advice. This study was funded by an NSF Graduate Fellowship (to SP), and grants from Sigma Xi (SP), the L.S.B. Leakey Foundation (JHM), NSF (BNS-8816132 to JHM), the Rackham School of Graduate Studies (SP and JHM), and the Evolution and Human Behavior Program (SP and JHM). Cayo Santiago was supported by the University of Puerto Rico Medical Sciences Campus, and NIH grant P40-RR03640-03.

\section{REFERENCES}

Altmann, J., 1974. Observational study of behavior: sampling methods. Behaviour, 49: 227-265. Altmann, S. A., 1962. A field study of the sociobiology of rhesus monkeys (Macaca mulatta). Ann. NY Acad. Sci., 102: 338-435.

Anderson, C., 1986. Female age: male preference and reproductive success in primates. Int. $J$. Primatol., 7: 305-326. 
Bielert, C. \& L. Girolami, 1986. Experimental assessments of behavioral and anatomical components of female chacma baboon (Papio ursinus) sexual attractiveness. Psychoneuroendocrinology, 11: $75-90$.

studies with adolescent and adult females as visual stimuli. Develop. Psychobiol, 19: $369-383$.

CATChPOle, H. R. \& G. van Wagenen, 1978. Reproduction in rhesus monkeys, Macaca mulatta. In: The Rhesus Monkey, G. H. Bourne (ed.), Academic Press, New York, pp. 118-139.

CHAPAIS, B., 1983. Reproductive activity in relation to male dominance and likelihood of ovulation in rhesus monkeys. Behav. Ecol. Sociobiol., 12: 215-228.

DATTA, S. B., 1983. Relative power and the maintenance of dominance. In: Primate Social Relationships: An Integrated Approach, R. A. HindE (ed.), Blackwell, Oxford, pp. 103-111.

FoSTER, D. L., 1977. Luteinizing hormone and progesterone secretion during sexual maturation of the rhesus monkey: short luteal phases during the initial menstrual cycles. Biol. Reprod., 17: $584-590$.

GLICK, B., 1980. Ontogenetic and psychobiological aspects of the mating activities of male Macaca radiata. In: The Macaques, D. LindBurg (ed.), Von Nostrand, New York, pp. 345-370.

Goodall, J., 1986. The Chimpanzees of Gombe. Belknap, Cambridge, Massachusetts.

GoRdON, T. P., 1981. Reproductive behavior in the rhesus monkey: social and endocrinological variables. Amer. Zool., 21: 185-195.

Halliday, T. R., 1983. The study of mate choice. In: Mate Choice, P. Bateson (ed.), Cambridge Univ. Press, Cambridge, pp. 3-32.

Hanby, J. P. \& C. E. Brown, 1974. The development of sociosexual behaviours in Japanese macaques Macaca fuscata. Behaviour, 49: 152-196.

HindE, R. A. \& S. AtKINSON, 1970. Assessing the roles of social partners in maintaining mutual proximity as exemplified by mother-infant relations in rhesus monkeys. Anim. Behav., 18: $169-176$.

LANCASTER, J., 1986. Human adolescence and reproduction: an evolutionary perspective. In: School Age Pregnancy and Parenthood: Biosocial Dimensions, J. Lancaster \& B. Hamburg (eds.), Aldine, New York, pp. 17-37.

Manson, J. H., 1992. Measuring female mate choice in Cayo Santiago rhesus macaques. Anim. Behav., 44: $405-416$.

- , 1994. Male aggression: a cost of female mate choice in Cayo Santiago rhesus macaques. Anim. Behav., 48: 473-475.

\& S. PERRY, 1993. Inbreeding avoidance in rhesus macaques: whose choice? Amer. J. Phys. Anthropol., 90: $335-344$.

PACKER, C., 1979. Inter-troop transfer and inbreeding avoidance in Papio anubis. Anim. Behav., 27: $1-36$.

Pusey, A., 1978. The physical and social development of wild adolescent chimpanzees (Pan troglodytes schweinfurthii). Ph.D. Diss., Stanford Univ., California.

Ransom, T. W., 1981. Beach Troop of the Gombe. Bucknell Univ. Press, Lewisburg, Pennsylvania.

RASMUSSEN, K. L. R., 1983. Age-related variation in interactions of yellow baboons. In: Primate Social Relationships: An Integrated Approach, R. A. Hinde (ed.), Blackwell, Oxford, pp. $47-52$.

Rawlins, R. G. \& M. Kessler, 1986. The history of the Cayo Santiago colony. In: The Cayo Santiago Macaques, R. G. Rawlins \& M. J. Kessler (eds.), SUNY Press, Albany, pp. $13-45$.

SAde, D. S., B. D. Chepko-SAde, J. M. Schneider, S. S. Roberts, \& J. T. RichtSmeier, 1985. Basic Demographic Observations on Free-ranging Rhesus Monkeys. HRAF Press, New Haven, Connecticut.

SCotT, L. M., 1984. Reproductive behavior of adolescent female baboons (Papio anubis) in Kenya. In: Female Primates: Studies by Women Primatologists, M. Small (ed.), Academic Press, New York, pp. $77-100$.

Smuts, B. B., 1985. Sex and Friendship in Baboons. Aldine, Hawthorne, New York.

\& R. W. Smuts, 1992. Male aggression and sexual coercion of females in nonhuman primates and other mammals: evidence and theoretical implications. In: Advances in the Study of Behavior, Vol. 22, P. J. B. Slater, J. S. Rosenblatt, M. Milinski, \& C. T. Snowdon (eds.), Academic Press, New York, pp. 1-63. 
SNedecor, G. W. \& W. G. Cochran, 1989. Statistical Methods. (8th ed.), Iowa State Univ. Press, Ames, Iowa.

VAN NoORDwIJk, M. A., 1985. Sexual behaviour of Sumatran long-tailed macaques (Macaca fascicularis). Z. Tierpsychol., 70: 277-296.

W ATTS, D. P., 1990. Mountain gorilla reproduction and social behavior. Amer. J. Primatol., 24: $211-225$.

Wilson, M. E., T. P. Gordon, \& D. C. Collins, 1982. Age differences in copulatory behavior and serum 17 $\beta$-estradiol in female rhesus monkeys. Physiol. Behav., 28: 733-737.

WolfE, L., 1978. Age and sexual behavior of Japanese macaques (Macaca fuscata). Arch. Sex. Behav., 7: 55-68.

L Received: November 7, 1993; Accepted: July 2, 1994

Authors' Names and Present Address: Susan Perry and Joseph H. Manson, Department of Anthropology, University of California, Los Angeles, California 90024-1553, U. S. A. 